2. Dimou FM, Eckelbarger D, Riall TS. Surgeon burnout: a systematic review. J Am Coll Surg. 2016;222:1230-9.

3. Ikonomidis JS, Boden N, Atluri P. The Society of Thoracic Surgeons Thoracic Surgery practice and access task force-2019 workforce report. Ann Thorac Surg. May 10, 2020 [Epub ahead of print].
4. Swain JD, Soegaard Ballester JM, Luc JGY, Han JJ. Burning the candle at both ends: mitigating surgeon burnout at the training stages. J Thorac Cardiovasc Surg. 2021;162:637-42.

5. Qquendo MA, Bernstein CA, Mayer LES. A key differential diagnosis for physicians—major depression or burnout? JAMA Psychiatry. 2019;76:111.
See Article page 637.

\section{Commentary: Oxygen masks, counterculture revolutions, and cardiothoracic surgery trainees}

\author{
Elizabeth H. Stephens, MD, PhD
}

During every in-flight safety briefing, we hear the same refrain, "in the event of a loss of cabin pressure, put on your oxygen mask before assisting your children." The concept applies to cardiothoracic surgeons: to optimally care for our patients, we must put on our own mask first.

Swain and colleagues ${ }^{1}$ provide a review of burnout, with reflections from a training perspective. Although the paper covers familiar topics and reflects on how such issues can affect trainees, to my eyes the paper overlooks the elephant in the room: the broader culture in which the trainee resides. Cardiothoracic surgery is a high-risk, high-reward specialty that draws intense personalities that often thrive on adrenaline, danger, challenges, and the demand for perfection. Our culture is built on a history of almost-mythological giants who dared to dream big, took often unfathomable risks, and whose lifestyles reflected immense sacrifice for their dreams. The accounts of these giants live on, with the details of training under the icons of DeBakey, Cooley, Kirklin, Lillehei, Spencer, Sabiston, and many others, passed on to each freshly minted intern at their respective institution. The intensity and demands of training have been

From the Department of Cardiovascular Surgery, Mayo Clinic, Rochester, Minn. Disclosures: The author reported no conflicts of interest.

The Journal policy requires editors and reviewers to disclose conflicts of interest and to decline handling or reviewing manuscripts for which they may have a conflict of interest. The editors and reviewers of this article have no conflicts of interest.

Received for publication June 25, 2020; revisions received June 25, 2020; accepted for publication June 26, 2020; available ahead of print July 14, 2020.

Address for reprints: Elizabeth H. Stephens, MD, PhD, Department of Cardiovascular Surgery, Mayo Clinic, 200 First St, SW, Rochester, MN 55905 (E-mail: stephens. elizabeth@mayo.edu).

J Thorac Cardiovasc Surg 2021;162:644-5

$0022-5223 / \$ 36.00$

Copyright (c) 2020 by The American Association for Thoracic Surgery

https://doi.org/10.1016/j.jtcvs.2020.06.105
Check for updates

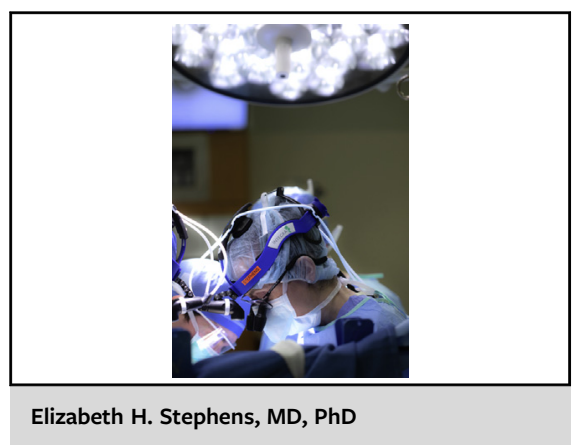

CENTRAL MESSAGE

Developing habits that

strengthen our fortitude as

cardiothoracic surgeons and

enable us to maintain peak per-

formance can run counter to the

culture in which we reside.

drastically curtailed, but the history in which we grow up remains, and the culture is slower to change. As part of this culture there is a masochism that is pervasive; it is exemplified by certain attendings, touted as a virtue by the staff who work with them, and often glorified among trainees. The trainee who sacrifices food, sleep, their personal commitments, etc, to go above and beyond for the sake of clinical duty is praised and rewarded. This isn't to say that sacrifice for the care of our patients isn't important- "the patient comes first" is in fact a founding tenant of my institution-but the issue becomes when such sacrifice goes to such lengths that it becomes detrimental to the trainee and/or the patient. For those in training eager to excel and gain the recognition of their attendings and outshine their peers, traits that potentially can become harmful can become entrenched. These traits are even more exaggerated when training at a high-octane academic institution with attendings frequently chasing after the illusive triple threat. 
The second, related component of the culture that the trainee grows up in pertinent to this discussion is the myth that cardiothoracic surgeons are indefatigable, indestructible, and immune to failure. Humans do need periodic breaks and hydration, but cardiothoracic surgeons don't?! Others benefit from adequate sleep, but in our specialty we can and are expected to operate on minimal or no sleep. Other physicians need to develop healthy habits for dealing with stress and a heavy workload, but we don't?! This culture isn't just present among attendings, or transmitted between attendings and trainees, but also develops among resident cohorts. Clearly, each institution and trainee class will have a distinct culture, but these underlying currents remain.

So how does "wellness" fit into this high-risk, highreward, demanding culture? Unfortunately, it does not fit very well. It's not surprising that institutionally enforced "wellness" activities are sometimes disparaged. And perhaps part of this is perspective. While such terms as "wellness" and "burnout" may seem unpalatable to the cardiothoracic surgeon, we all strive for peak performance every day, and elements that detract from that-whether they be emotional, psychological, or physical—should be viewed as opportunities for improvement. Thus, developing habits that strengthen our "wellness," ie, resilience or fortitude (words that I prefer) and enable us to maintain peak performance are essential-that is the type of "wellness" that cardiothoracic surgeons desire.

The questions then become for the trainee (1) how do you recognize if and when certain behaviors, that are often inherently good (ie, work-ethic, devotion to patient care) are becoming harmful, (2) how to develop habits to optimize your performance and fortitude and avoid burnout, (3) when and how to counteract a culture that may perpetuate habits that could be harmful, and (4) how to find help when such measures may be encouraged at an institutional-level but discouraged within our specialty culture. The reality is, habits that begin during training can be hard to break. As an attending cardiothoracic surgeon, the stress is considerably greater, the hours are frequently worse, and the institutional culture may not always cultivate traits conducive for optimal performance. The current generation of trainees has an opportunity to set a new example and develop healthy habits, even if it is counter to the culture in which they find themselves. At times the best care of the patient is not working longer hours or clinically pushing oneself, but putting the mask on ourselves so we can better help our patients.

\section{Reference}

1. Swain JD, Ballester JMS, Luc JGY, Han JJ. Burning the candle at both ends: mitigating surgeon burnout at the training stages. J Thorac Cardiovasc Surg. 2021; 162:637-42. 